\title{
Airborne Sunphotometer, Airborne in-situ, Space-borne, and Ground-based Measurements of Tropospheric Aerosol in ACE-2
}

\author{
B. Schmid ${ }^{1}$, D. Collins ${ }^{2}$, S. Gass6 ${ }^{3}$, E. Öström ${ }^{4}$, D. Powell ${ }^{5}$, E. Welton ${ }^{6}$, P. Durkee ${ }^{7}$, J. Livingston ${ }^{8}$, P. Russell ${ }^{9}$, R. Flagan ${ }^{10}$, J.
} Seinfeld $^{10}$, D. Hegg ${ }^{3}$, K. Noone ${ }^{11}$, K. Voss ${ }^{12}$, J. Reagan ${ }^{3}$, J. Spinhirne ${ }^{13}$, D.M. McIntosh ${ }^{14}$

${ }^{1}$ Bay Area Environmental Research Institute, 3430 Noriega Street, San Francisco CA 94122, USA

P: (650) 604-5933, F: (650) 604-3625, e-mail: bschmid@mail.arc.nasa.gov

${ }^{2}$ Texas A\&M University, David G. Eller O\&M Bldg, College Station, TX 77843, USA

${ }^{3}$ University of Washington, Box 351650 , Seattle, WA 98195 , USA

${ }^{4}$ Hadley Centre for Climate Prediction and Research, Meteorological Office, Bracknell, Berkshire RG12 2SY, UK

${ }^{5}$ University of Arizona, ECE Building, Tucson, AZ 85721, USA

${ }^{6}$ Science Systems and Application Inc., NASA/GSFC Code 912, Greenbelt, MD 20771, USA

' Naval Postgraduate School, 589 Dyer Road, Monterey, CA 93943, USA

${ }^{8}$ SRI International, 333 Ravenswood Avenue, Menlo Park, CA 94025, USA

'NASA Ames Research Center, MS 245-5, Moffett Field, CA 94035, USA

${ }^{10}$ California Institute of Technology, 1200 East California Boulevard, Pasadena, CA 91125, USA

${ }^{11}$ Meteorological Institute Stockholm University, Arthenius Lab, Stockholm, 10691 Sweden

${ }^{12}$ University of Miami, 1320 Campo Sano Dr., Coral Gables, FL 33146, USA

${ }^{13}$ NASA Goddard Space Flight Center, Code 912, Greenbelt, MD 20771, USA

${ }^{14}$ Symtech Corporation, 2750 Eisenhower Ave., Suite 104 Alexandria, VA 22314, USA

\section{INTRODUCTION}

The North Atlantic Regional Aerosol Characterization Experiment (ACE-2) of the International Global Atmospheric Chemistry Project (IGAC) ran from 16 June to 25 July 1997. The results presented in this study are part of the "Clear-sky column closure experiment" (CLEARCOLUMN) activity, one of 6 ACE-2 activities [1]. Clear-sky column closure experiments call for characterization of aerosol layers by simultaneous measurements using different techniques that can be related using models [2].

A wide range of aerosol types was encountered throughout the ACE-2 area, including background Atlantic marine, European pollution-derived and African mineral dust. In a series of papers, we reported on ACE-2 CLEARCOLUMN results obtained by combining airborne sunphotometer and in-situ measurements taken aboard the Pelican aircraft, spaceborne NOAAVAVHRR data and ground-based lidar and sunphotometer measurements [3]-[10]. Those and other CLEARCOLUMN results have been summarized in [11].

In this paper we only report on results not shown in this form in [3]-[11].

\section{METHODOLOGY}

We are using several different techniques to determine aerosol optical depth (AOD), extinction and size distributions of aerosol layers:

1) The NASA Ames Airborne Tracking 14-channel Sunphotometer (AATS-14) can determine the AOD above the airplane at 13 wavelengths between $(380$ to $1558 \mathrm{~nm})$. AOD vertical profiles obtained during narrow up or down spirals can be differentiated to obtain extinction profiles [9].
Layer AODs or extinction spectra can be inverted to retrieve size distributions.

2) Continuous airborne size distribution measurements $(\mathrm{D}=5 \mathrm{~nm}-8 \mu \mathrm{m})$ corrected to ambient $\mathrm{RH}$ together with measured/assumed composition information can be used to compute extinction and layer AOD using Mie theory [3].

3) Three airborne nephelometers measured scattering coefficients at different $\mathrm{RH}$ (allowing correction to ambient RH) [5],[7]. Corrections for inlet-cutoff, light-source and angular truncation need to be applied, using information from 2) [3], [9]. Absorption coefficients have been measured by an airborne particle soot absorption photometer (PSAP) [7]. Corrections for scattering contributions and inlet-cutoff need to be applied based on the results from 2) and the nephelometers [3], [9]. Extinction is then obtained by adding absorption and scattering coefficients.

4) Ground based Micro-Pulse Lidars measure extinction or AOD profiles [8], [10].

\section{RESULTS}

On July 17,1997 , a vertical profile flown near Tenerife (Canary Islands) in a cloud free air mass reveals three distinctly different layers: a somewhat polluted marine boundary layer (MBL), an elevated dust layer and a very clean layer between the MBL and the dust layer. Figure 1 shows the AOD and extinction ( $\lambda \cong 525 \mathrm{~nm}$ ) obtained using the four different techniques. Note that the integrated extinctions for techniques 2 and 3 yield layer AODs only and the AATS-14 AOD value obtained at the top of the profile was added to facilitate comparison. The lidar data show that the elevated dust layer extended above the Pelican's maximum flight altitude. 

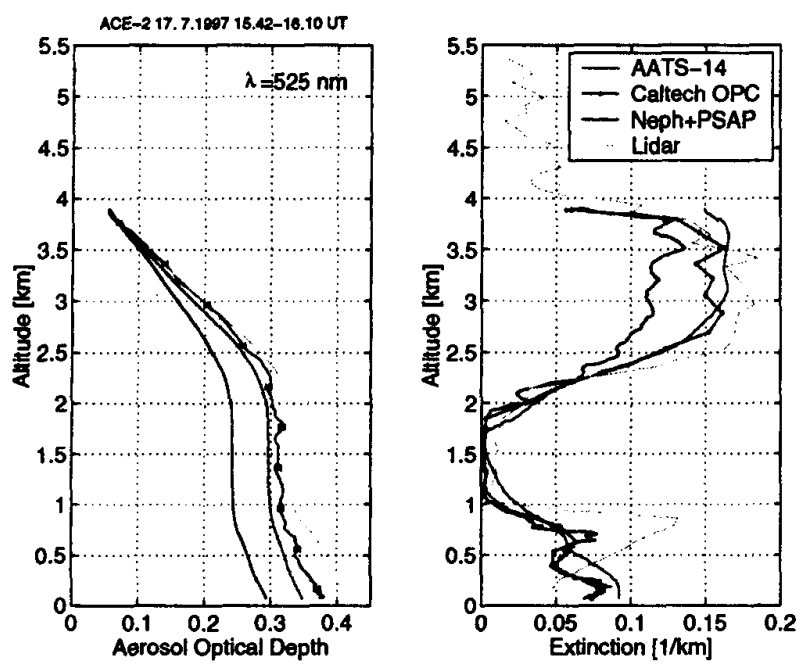

Figure 1: Aerosol optical depth and extinction profile off Tenerife retrieved from AATS-14, from size distribution measurements, and by combining scattering and absorption measurements of 3 nephelometers and the PSAP instrument during Pelican flight tf20 on July 17, 1997. Also shown is the profile obtained with a nearby $(24 \mathrm{~km})$ Micro Pulse Lidar.

With the exception of a few points, the Caltech OPC extinctions (technique 2) agree with the AATS-14 results throughout the entire profile within the error bars of both techniques. The agreement between nephelometer/PSAP and AATS-14 extincion is outside the error bars [9] in the dust layer, but within error bars for most of the MBL. Above the MBL the lidar AOD and extinctions agree well with the AATS-14 and the Caltech OPC results. Near the top of the MBL the lidar shows considerably larger extinction than the other techniques. This might be caused by the spatial separation $(24 \mathrm{~km})$ of the profiles.

The layer AOD comparisons for the dust and MBL are shown in Figure 2 and Figure 3. In the MBL, the layer AODs obtained with the four techniques agree within the combined error bars. The layer AODs obtained with in-situ techniques (Caltech OPC and Nephelometer/PSAP) tend to be lower than the remote sensing results (AATS-14 and Lidar). In the dust (Figure 3), the layer AODs of Caltech and AATS-14 agree almost perfectly at all wavelengths except at $1558 \mathrm{~nm}$. The lidar AOD agrees very well with the Caltech and AATS14 results. The nephelometer/PSAP AODs are lower by $20 \%$ $38 \%$. Only the result at the shortest nephelometer wavelength agrees within the error bars. The nephelometer/PSAP layer AOD spectrum is also much steeper.

Instead of computing extinction from the in-situ sizedistribution data and comparing this with the extinction or layer AOD obtained from AATS-14, we may compare size distributions by inverting the AATS-14 extinction or layer AOD spectra.

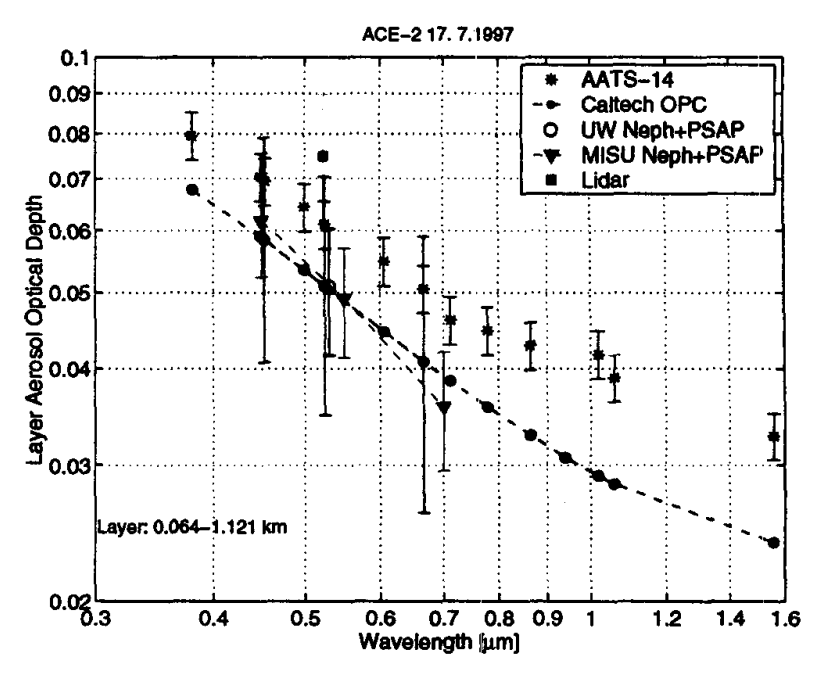

Figure 2: Spectral aerosol optical depth for the MBL (64$1121 \mathrm{~m}$ a.s.l.) shown in Figure 1.

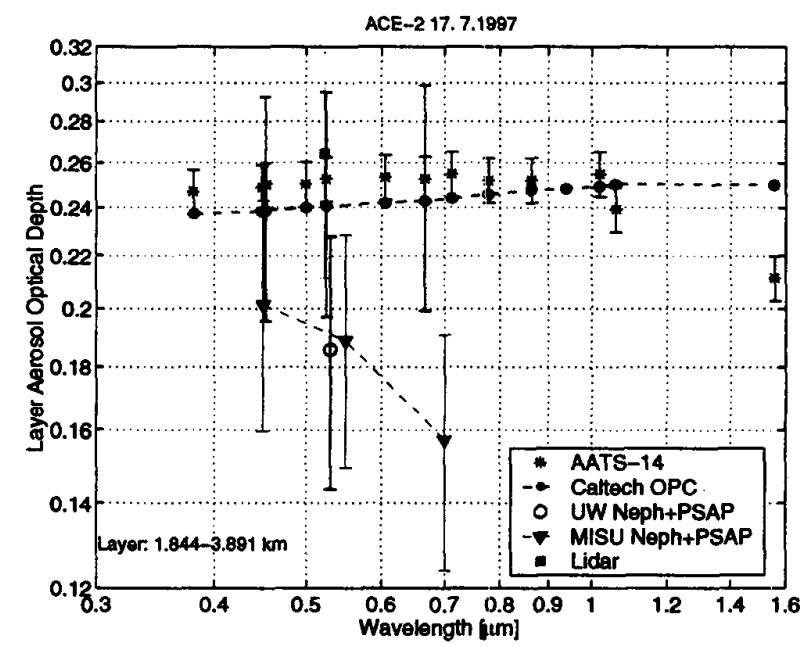

Figure 3: Spectral aerosol optical depth for part of the dust layer (1844-3891 m a.s.l.) shown in Figure 1.

We have used two different inversion methods: the widely used King constrained linear inversion method [12] and a method that varies the amplitudes of a predetermined multimodal lognormal size distribution (mode radii and widths remain fixed and are chosen according to an aerosol climatology by Remer et al. [13]). The results for the July 17, 1997 MBL are shown in Figure 4, in terms of area size distributions. A wavelength-independent refractive index of $m=1.4-0.0035 i$ has been used with both inversion methods. The agreement between the in-situ data and the King inversion is within error bars for two thirds of the size bins. 


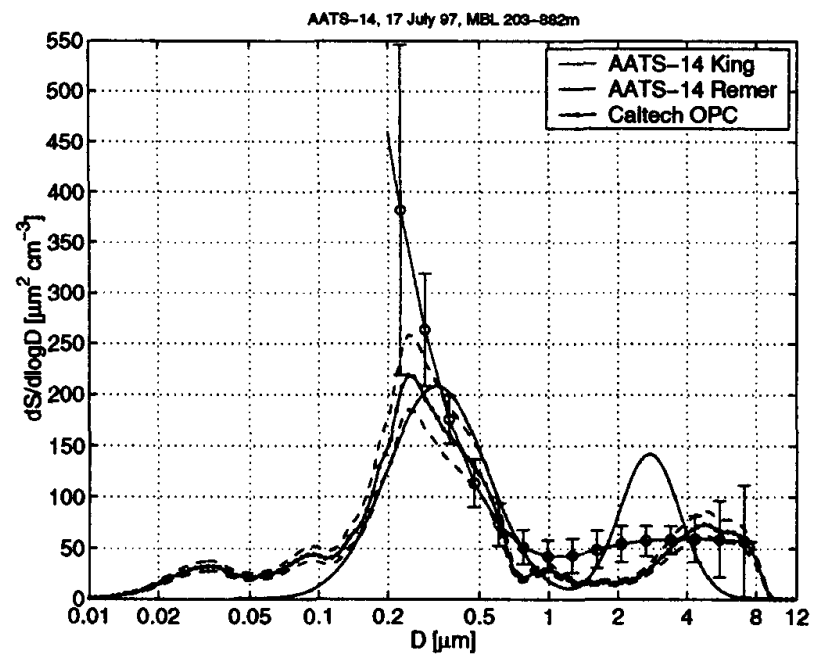

Figure 4: Comparison of MBL area size distributions from insitu measurements and from inverted AATS-14 spectral extinction measurements (using two different inversion methods, see text) during Pelican flight tf20 on July 17, 1997. Dashed lines indicate uncertainties of the Caltech results.

No error bars are available yet for the fixed mode-radii inversion. But especially the result for the accumulation mode is in very good agreement with the in-situ size distribution. The AATS-14 size distributions obtained using the King method cover only the size range where the aerosol particles are optically active. The fixed mode-radii inversion allows a physically sound extrapolation to smaller and larger sizes.

\section{CONCLUSIONS}

In most cases we find closure among extinction or AOD measured using AATS-14 and computations based on continuous size distribution measurements on the same aircraft [3], [10]. However, considerable effort is required to arrive at ambient extinction from measured size distributions of a partially dried aerosol.

The fact that the nephelometers and the PSAP sampled the aerosol through an inlet with an aerodynamic diameter cut-off of $2.5 \mu \mathrm{m}$ makes those measurements less useful for the closure study carried out here. Large corrections (especially in the dust) had to be applied. Therefore, it is not surprising that closure with AATS-14 was not always achieved.

Closure between AATS-14 and lidar was achieved in the dust layer for the case shown here and another one discussed in [9] and [10].

Aerosol size-distribution closure based on in-situ size distributions and inverted AATS-14 extinction spectra (using the Method of King et al. [12]) has been achieved in the MBL. The results for a newly developed fixed mode-radii inversion technique are promising but need more validation.

\section{REFERENCES}

[1] F. Raes, T. Bates, F. McGovern, and M. Vanliedekerke, "The second Aerosol Chatacterization Experiment (ACE-2): General context and main results," Tellus, B2, pp. xxx, April 2000.

[2] P.K. Quinn et al., "Closure in Tropospheric AerosolClimate Research: A Review and Future Needs for Addressing Aerosol Direct Shortwave Radiative Forcing." Contrib. Atmosph. Phys., vol. 69, pp. 547577.1996.

[3] D.R. Collins et al., "In situ aerosol size distributions and clear column radiative closure during ACE-2." Tellus, B2, pp. xxx, April 2000.

[4] P.A. Durkee et al., "Regional aerosol properties from satellite observations: ACE-1, TARFOX and ACE-2 results." Tellus, B2, pp. xxx, April 2000.

[5] S. Gass 6 et al., "Influence of humidity on the aerosol scattering coefficient and its effect on the upwelling radiance during ACE2." Tellus, B2, pp. xxx, April 2000.

[6] J.M. Livingston et al., "Shipboard Sunphotometer Measurements of Aerosol Optical Depth Spectra during ACE-2." Tellus, B2, pp. xxx, April 2000.

[7] E. Öström, and K.J. Noone, "Vertical profiles of aerosol scattering and absorption measured in situ during the North Atlantic Aerosol Characterization Experiment." Tellus, B2, pp. xxx, April 2000.

[8] D.M. Powell, J. A. Reagan, M. A. Rubio, W. H. Erxleben, and J. D. Spinhirne, "ACE-2 multiple angle Micro-Pulse Lidar observations from Las Galletas, Tenerife, Canary Islands." Tellus, B2, pp. xxx, April 2000.

[9] B. Schmid et al., "Clear sky closure studies of lower tropospheric aerosol and water vapor during ACE-2 using airborne sunphotometer, airborne in-situ, spaceborne, and ground-based measurements." Tellus, B2, pp. xxx, April 2000.

[10] E.J. Welton et al. "Ground-based lidar measurements of aerosols during ACE-2: lidar description, results, and comparisons with other ground-based and airborne measurements." Tellus, B2, pp. xxx, April 2000.

[11] P.B. Russell, and J. Heintzenberg, "An Overview of the ACE 2 Clear Sky Column Closure Experiment (CLEARCOLUMN)." Tellus, B2, pp. xxx, April 2000.

[12] M.D. King, D.M. Byrne, B.M. Herman and J.A. Reagan, "Aerosol Size Distributions Obtained by Inversion of Spectral Optical Depth Measurements." J. Atmos. Sci., vol. 35, pp. 2153-2167, 1978.

[13] L.A. Remer, Y.J. Kaufman and B.N. Holben, "Interannual variation of ambient aerosol characteristics on the east coast of the United States." J. Geophys. Res., vol. 104, No. D2, pp. 2223-2231, January 27, 1999. 